\title{
Estimation of Radar Cross Sectional Area of Target using Simulation Algorithm
}

\author{
Tarig Ibrahim Osman Ahmed ${ }^{1 *}$, Moutaman Mirghani² \\ ${ }^{1}$ Assistant Professor, Alrayyan College, Saudi Arabia. \\ ${ }^{2}$ Associate Professor, Institute of Space Research and Aerospace, Sudan.
}

*Corresponding Author: Tarig Ibrahim Osman Ahmed, Assistant Professor, Alrayyan College, Saudi Arabia

\begin{abstract}
This paper presents an Estimation of Radar Cross Sectional Area of Target using Simulation Algorithm. Most radar systems use RCS as a means of discrimination. Therefore, accurate prediction of target RCS is critical in order to design and develop robust discrimination algorithms. Additionally, measuring and identifying the scattering centers (sources) for a given target aid in developing RCS reduction techniques. Another reason of lesser importance is that RCS calculations require broad and extensive technical knowledge, thus many scientists and scholars find the subject challenging and intellectually motivating. Two categories of RCS prediction methods are available:

- Exact prediction methods.

- Approximate prediction methods.

Exact methods of RCS prediction are very complex even for simple shape objects. This is because they require solving either differential or integral equations that describe the scattered waves from an object under the proper set of boundary conditions. Such boundary conditions are governed by Maxwell's equations. Even when exact solutions are achievable, they are often difficult to interpret and to program using digital computers. Due to the difficulties associated with the exact RCS prediction, approximate methods become the viable alternative. The majority of the approximate methods are valid in the optical region, and each has its own strengths and limitations. Most approximate methods can predict RCS within few decibels of the truth. In general, such a variation is quite acceptable by radar engineers and designers. Approximate methods are usually the main source for predicting RCS of complex and extended targets such as aircrafts, ships, and missiles. When experimental results are available, they can be used to validate and verify the approximations. Some of the most commonly used approximate methods are Geometrical Optics (GO), Physical Optics (PO), Geometrical Theory of Diffraction (GTD), Physical Theory of Diffraction (PTD), and Method of Equivalent Currents (MEC) so in this paper we try to Estimate a Radar Cross Sectional Area of Target using Simulation Algorithm.
\end{abstract}

\section{INTRODUCTION}

Radar cross section (RCS) is the measure of a target's ability to reflect radar signals in the direction of the radar receiver, i.e. it is a measure of the ratio of backscatter power per unit solid angle in the direction of the radar (from the target) to the power density that is intercepted by the target ${ }_{[1]}$.

The RCS of a target can be viewed as a comparison of the strength of the reflected signal from a target to the reflected signal from a perfectly smooth sphere of cross sectional area of $1 \mathrm{~m}^{2}$ as shown in Figure 1:

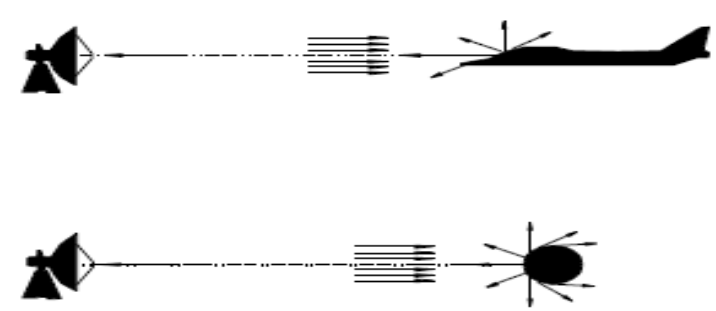

Figure1. Concept of Radar Cross Section

International Journal of Research Studies in Electrical and Electronics Engineering (IJRSEEE) Page | 20 
RCS, denoted by the Greek letter $\sigma$ and measured in $\mathrm{m}^{2}$, is defined as:

$\sigma=4 \Pi \frac{p s}{p i} \ldots$

$\mathrm{Pi}:=$ power density, or intensity, of a plane wave striking the target.

Ps: = power per unit solid angle reflected by the target.

RCS has a wide spread ranging from $10^{-5}$ for small insects to $10^{6}$ for large ships. Hence, RCS is often stated in the logarithmic decibel scale:

$$
\sigma_{d b}=10 \log \left(\frac{\sigma}{1 . m^{2}}\right) \ldots
$$

\section{RCS is a function of}

- Position of transmitter/receiver relative to target.

- Target geometry and material composition.

- Angular orientation of target relative to transmitter/receiver.

- Frequency or wavelength.

- Antenna polarization.

The conceptual definition of RCS includes the fact that not all of the radiated energy falls on the target. A target's RCS (F) is most easily visualized as the product of three factors:

\section{$\sigma=$ Projected cross section $\mathrm{x}$ Reflectivity $\mathrm{x}$ Directivity.}

$\operatorname{RCS}(\sigma)$ is used above for an equation representing power reradiated from the target.

Reflectivity: The percent of intercepted power reradiated (scattered) by the target.

Directivity: The ratio of the power scattered back in the radar's direction to the power that would have been backscattered had the scattering been uniform in all directions.

Figures 2 and 3 show that RCS does not equal geometric area. For a sphere, the RCS, $\sigma=\Pi r^{2}$, where $r$ is the radius of the sphere.

The RCS of a sphere is independent of frequency if operating at sufficiently high frequencies where $\lambda<<$ Range, and $\lambda<<$ radius (r). Experimentally, radar return reflected from a target is compared to the Radar return reflected from a sphere which has a frontal or projected area of one square meter.

Using the spherical shape aids in field or laboratory measurements since orientation or positioning of the sphere will not affect radar reflection intensity measurements as a flat plate would. If calibrated, other sources (cylinder, flat plate, or corner reflector, etc.) could be used for comparative measurements. [2]

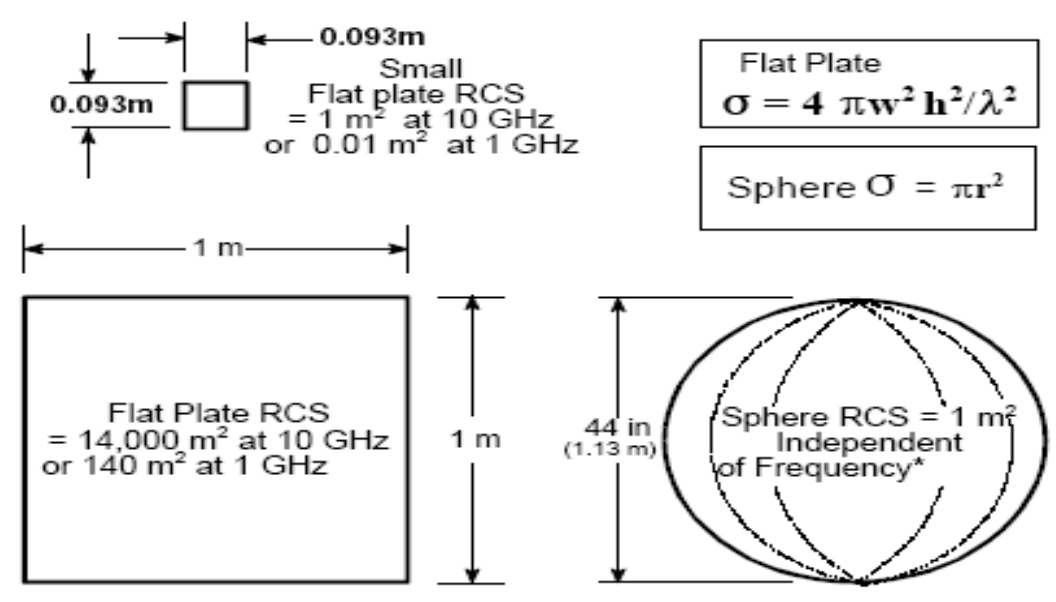

Figure2. RCS versus Physical Geometry

International Journal of Research Studies in Electrical and Hectronics Engineering (IJRSEEE) Page $\mid 21$ 


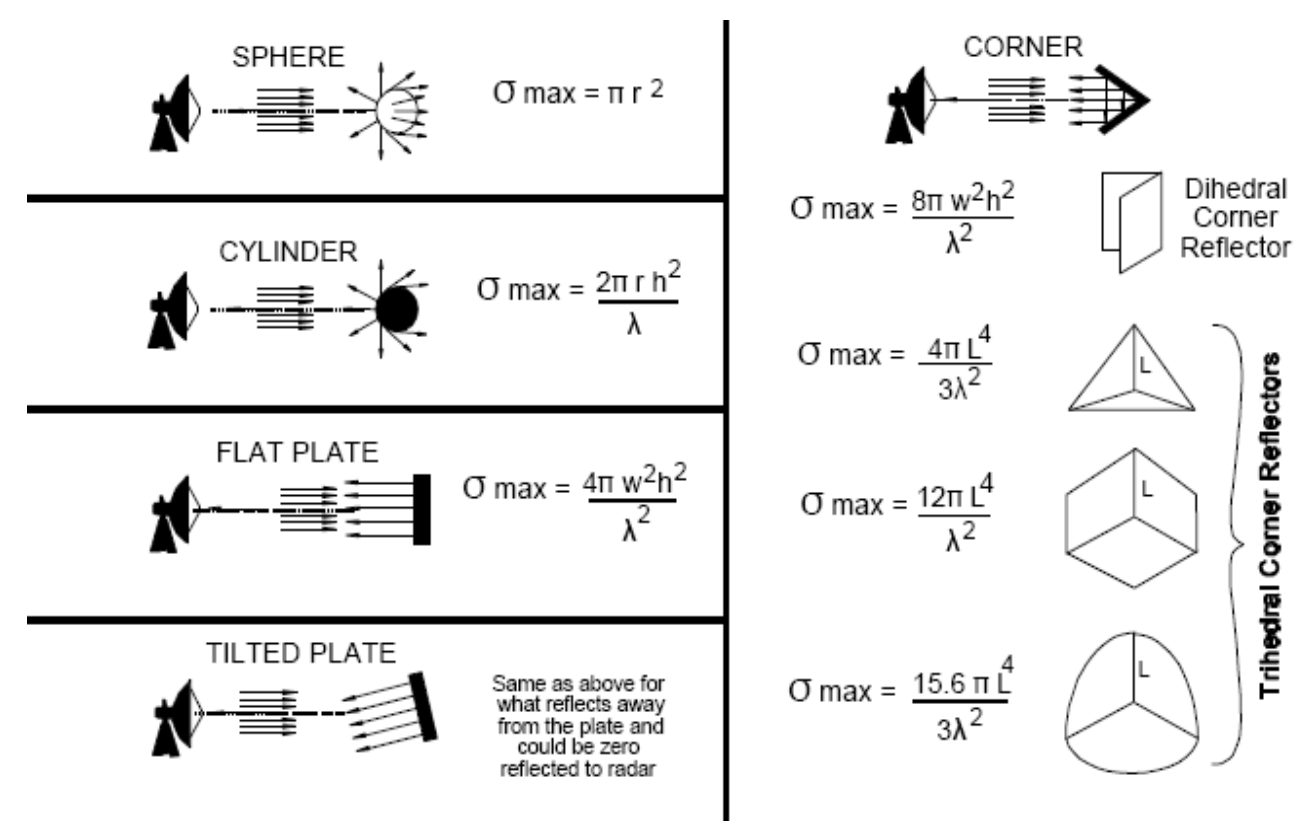

Figure3. Backscatter from Shapes

In Figure 4, RCS patterns are shown as objects are rotated about their vertical axes (the arrows indicate the direction of the radar reflections).

The sphere is essentially the same in all directions. The flat plate has almost no RCS except when aligned directly toward the radar. [4]

The corner reflector has an RCS almost as high as the flat plate but over a wider angle, i.e., over $\pm 60 \mathrm{E}$. The return from a corner reflector is analogous to that of a flat plate always being perpendicular to your collocated transmitter and receiver.

Targets such as ships and aircraft often have many effective corners. Corners are sometimes used as calibration targets or as decoys, i.e. corner reflectors. An aircraft target is very complex. It has a great many reflecting elements and shapes. The RCS of real aircraft must be measured. It varies significantly depending upon the direction of the illuminating radar. [6]

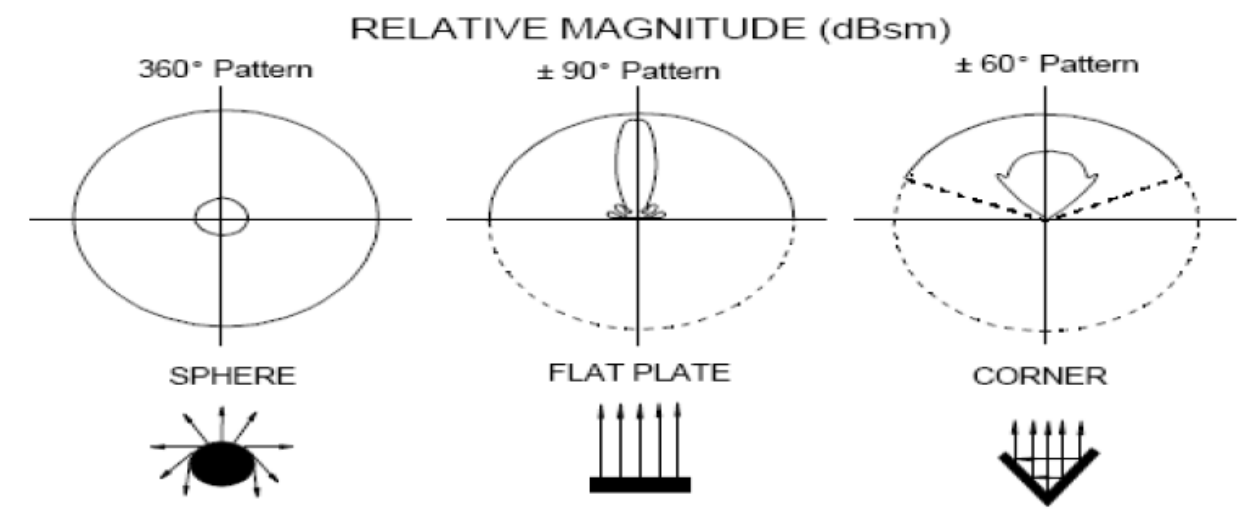

Figure4. RCS Patterns

\section{ReSUlTS}

The developed method for point scatter modeling based on RCS measurements can be summarized in three steps:

1. Target examination The RCS properties of the target are examined in order to determine which parts of the target that should be considered for modeling. By examining ISAR images of the target for certain aspects, e.g. every 15, regions showing dominant and persistent scattering can be localized. Since dominant scattering is decisive for the position of the radar target centre, and persistent scattering reduces the number of points needed for modeling the target's radar cross section, it's important that such areas of the target are found and considered for modeling. 
2. Point scattered configuration A set of point scatters is created, where each scattered is defined by its position and aspect-dependent radar cross section. The coordinates are defined according to the bright, persistent scattering centers that have been located. The RCS assigned to each point scattered is estimated in Know bell as the radar cross section contained within an arbitrarily defined region of the radar target image. When determining the point scattered region, concern should be taken to the region's geometry and the variation of RCS inside, for different aspects. A region containing two or more separated, dominant scattering locations should be divided into smaller regions. The size and shape of these regions depend on the locations of the scattering. Finer division of the scattering regions generally leads to better results as long as only clearly separated, dominant scattering areas are considered. A large target with scattering distributed over wide areas will naturally demand more point scatters than a small target, since distributed RCS needs to be modeled by multiple point scatters.

3. Model validation the model is validated by calculating the radar target centre for different target aspects and comparing the location with the true position given by ISAR images of the target at the same viewing angles.

\section{CONCLuSion}

In This paper has presented a method for point scattered modeling where the proposed method has application to target-seeker simulations. The method has been proved to be best suited for radar targets with large radar cross section. Target scattering localized to bright and persistent scattering centers, is easily modeled by a small number of point scatters. If some parts of the target are dominating the total radar cross section, for all possible aspects, these regions alone can be considered for modeling. On the other hand, if the RCS is distributed or varying for different aspects, the complete target area needs to be modeled. Targets with very small radar cross section are on the other hand difficult to model by using the developed method, the Rund model fails to accurately describe the radar target centre for nose-on viewing angles where the radar cross section is so low that it's hard to distinguish the actual target. It's possible to improve the modeling of targets with small radar cross section in different ways. One way is to increase the transmitter power during the RCS measurements, this way the target is more easily detected. Next, background subtraction can be applied when generating ISAR images. If the RCS of the background is measured, it's possible to subtract this information from the target image. A few notes can be made about the use of the method for the background purpose of creating radar target models for target-seeker simulations. First of all, the method has to be extended to include RCS measurements of full-size objects in three dimensions. Thus, turntable data of real aircraft need to be collected for different elevation angles. Further, raw data signals from conventional target seekers are necessary for improved model validation, regarding both target positioning and classification. To sum up, the evaluated method of radar target modeling offers an easy way to produce computationally efficient models of air targets. The big disadvantage of the method is the lack of automation and optimization when characterizing point scatters.

\section{REFERENCES}

[1] B. C. Brock and A. W. Doerry, "Radar cross section of triangular trihedral reflector with extended bottom plate," 2009. View at Publisher · View at Google Scholar

[2] E. F. Knott, "RCS reduction of dihedral corners," IEEE Transactions on Antennas and Propagation, vol. 25, no. 3, pp. 406-409, 1977. View at Publisher · View at Google Scholar

[3] K. Hayashi, R. Sato, Y. Yamaguchi, and H. Yamada, "Polari metric scattering analysis for a finite dihedral corner reflector," IEICE Transactions on Communications, vol. E89-B, no. 1, pp. 191-195, 2006. View at Publisher · View at Google Scholar · View at Scopus

[4] P. Corona, A. de Bonitatubus, G. Ferrara, and C. Gennarelli, "A very accurate model for backscattering by right angled dihedral corners," in Proceedings of the IEEE Antennas and Propagation Society International Symposium, vol. 4, pp. 1734-1737, May 1990.

[5] P. Marinkovic, G. Ketelaar, F. van Leijen, and R. Hanssen, "InSAR quality control—analysis of five years of corner reflector time series," in Proceedings of the 5th International Workshop on ERS/Envisat SAR Interferometry (FRINGE '07), Frascati, Italy, November 2007.

[6] S. Y. Wang and S. K. Jeng, "Compact RCS formula for a dihedral corner reflector at arbitrary aspect angles," IEEE Transactions on Antennas and Propagation, vol. 46, no. 7, pp. 1112-1113, 1998. View at Publisher · View at Google Scholar · View at Scopus

International Journal of Research Studies in Electrical and Electronics Engineering (IJRSEEE) Page | 23 
[7] T. Y. Otoshi, "Study of microwave leakage through perforated flat plates," IEEE Transactions on Microwave Theory and Techniques, vol. 20, no. 3, pp. 235-236, 1972. View at Scopus

[8] X.-J. Shan, J.-Y. Yin, D.-L. Yu, C.-F. Li, J.-J. Zhao, and G.-F. Zhang, "Analysis of artificial corner reflector radar cross section: a physical optics perspective," Arabian Journal of Geosciences, 2012. View at Publisher · View at Google Scholar

\section{AUTHORS' BIOGRAPHY}

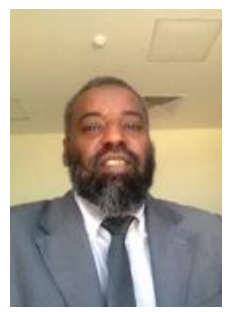

Tarig Ibrahim Osman Ahmed, Holds a BSc of Electrical and Computer Engineering from Omdurman University 1999. Worked as electronic engineer in Sudanese Currency Factory, and IT engineer in the National Computer Company (NARS), and worked as a teacher at Sudanese-Korean Institute of Technology. Holds a MSc of Electronic and Computer Engineering at Omdurman University 2008. Worked as lecturer at Al-Rayyan High Institute in Saudi Arabia, then as a lecturer at Tiba university, and Arab Open University. Also worked as electronic and IT engineer in the MAKAREM Al Madinah Hotel. Holds PhD of Electronic Engineering from Sudan Academy of Science, Currently an Assistant professor at Al Rayyan colleges, Saudi Arabia.

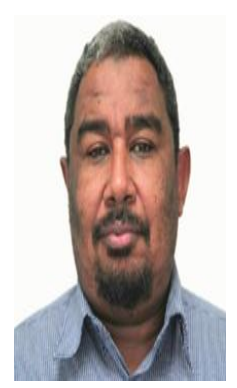

Moutaman Mirghani, currently is working as Associate Research Professor at the National Center for Research (NCR). He has been the Director of the Institute of Space Research and Aerospace (ISRA) since deputation to NCR from July 2013 till March 2018. Now, he teaches at the University of Khartoum both undergraduate and postgraduate students. He has been Associate Professor at Karary University since March 2011 till December 2013. Before, Moutaman has directed two research centers prior to ISRA. Also, has published two textbooks in Arabic and one in English, as well as many papers and articles on periodicals and journals, and supervised many academic research dissertations.

Citation: Tarig Ibrahim Osman Ahmed, Moutaman Mirghani. "Estimation of Radar Cross Sectional Area of Target using Simulation Algorithm", International Journal of Research Studies in Electrical and Electronics Engineering, 4(2), pp 20-24. DOI: http://dx.doi. org/10.20431/2454-9436.0402003

Copyright: (C) 2018 Authors. This is an open-access article distributed under the terms of the Creative Commons Attribution License, which permits unrestricted use, distribution, and reproduction in any medium, provided the original author and source are credited. 